\title{
Water Desalination Using Cellulosic Nano-filtration Membrane Composed of Nano-scale Polytetraflouroethylene
}

\author{
M.F. Shaaban ${ }^{1 *}$, M.A. El-Khateeb ${ }^{2}$ and M.A. Saad ${ }^{1}$ \\ ${ }^{1}$ Textile Research Division, National Research Centre, Dokki, Giza, Egypt. \\ ${ }^{2}$ Water Pollution Control Dept., National Research Centre, Dokki, Giza, Egypt.
}

\begin{abstract}
$\mathbf{T}$ HIS STUDY deals with the preparation and characterization of Nanofiltration cellulose acetate-based membranes and their application in desalination of brackish water. Cellulose acetate nanofiltration (CA-NF) membranes were prepared using phase inversion process. Pore size of the prepared membrane was checked via dope solutions of different polymer concentrations (wt. \%) and treatment temperatures from $60-90^{\circ} \mathrm{C}$. followed by casting the membrane on Polytetraflouroethylene sheets (PTFE) and examining the efficiency of the product. Characterization of the prepared membrane was carried out utilizing scanning electron microscopy (SEM). The work was extended to study the hydraulic permeability, water permeation as well as salt rejection percentage. Characterization of the prepared membrane will be carried out utilizing scanning electron microscopy (SEM), the hydraulic permeability, water permeation as well as salt rejection percentage. Results indicated that CA membranes reinforced with (PTFE) gave better efficiency than normal CA membranes.
\end{abstract}

Keywords: Desalination, Nanofiltration, Cellulose derivatives, Phase inversion process, Membrane.

\section{Introduction}

Nanofiltration membrane is considered as one of the pressure forced membrane that performs a preferential disconnection for different ions or fluids. Nanofiltration membrane pores are generally larger than those of reverse osmosis membranes. Therefore, nanofiltration needs less energy to perform such separation. The feasibility of nanofiltration membranes for the application in water and waste water treatment processes is brought about from their higher flux as well as lower operating pressure. [1]

Due to the shortage of clean drinking water worldwide, water desalination via nanofiltration (NF) and reverse osmosis (RO) membranes becomes the most suitable choice for desalinating brackish and sea water. Nevertheless, the enhancement in membranes emphasizes salt rejection and high fluxes using decreased pressures is of great importance. The precursor membrane composition has been manufactured using phase inversion technique from Cellulose Acetate (CA) and described by Durmaz et al. [2] cellulose acetate with low price and chlorine resistance represents the most interesting polymer.
On the other hand, CA is an eco-friendly product obtained from sustainable and biodegradable resources. The elaboration of membrane material having RO performances has been reported [3-6].

During the past decade, an intermediate nanofiltration method, applying extra open pores with decreased pressures, produced a selective retention among divalent to monovalent ions [7$10]$.

In contrast to other varieties of desalinating water, brackish water desalination is through some distance the most sophisticated and intricate process. It has the least water recovery percentage $(30-35 \%)$. Operation is restrictive to favorable operation circumstances. Also, it tends to need inclusive pretreatment, specifically if the input is obtained from an exposed seawater source place. This process consumes energy, and for all prementioned elements seawater desalination is the most expensive desalination way. The main reason for expensive cost and technological sophistication is the seawater itself which is distinct through having: (1) increased hardness content, (2) different degrees of turbidity, and (3) high dissolved salts at $\mathrm{pH}>8.0$. These characteristics show three main

\footnotetext{
*Corresponding author e-mail: drmohamed727@gmail.com

DOI: 10.21608/ejchem.2018.3738.1327

C2017 National Information and Documentation Center (NIDOC)
} 
problems in seawater desalination which yield tough restriction and have said outcomes at the overall performance and productivity of seawater desalination plants $[11,12]$.

At the present time, nanofiltration became the most widespread technique applied in drinking water industries [13] and wastewater treatment plants for the purpose of contaminants removal processes such as pesticides [14], Heavy metals [15], leachate soil [16] and dyestuff residues [17]. As well as for food applications [18] and biotechnological process. Interfacial polymerization (IP) technique is considered one of the most successful techniques used in composite nanofiltration membranes preparation, which have high salt rejection water and permeation flux. There are a huge number of advantages in membrane designing through using the IP process [19].

Cellulose acetate membrane gets to be those initial unreasonable in general execution uneven membrane. It has been comprehensively utilized for microfiltration (MF), reverse osmosis (RO), Furthermore gas segregation. Cellulose acetate membranes have high hydrophilicity which plays an important role in decreasing besmirch, enhanced resistivity to solvent and chlorine. The regenerated CA membrane which altered to be hydrolyzed from CA has appreciably improved thermal stability and solvent-impedance[20].

Commercial CA membranes would whichever even sheet or spiral-wound modules. The hollow fiber arrangement has elicited as a preferable preference due to the hollow fiber membranes have three distinct benefits:

A- Hollow fiber modules have much bigger proportion for membrane area per unit volume (many. thousand), and therefore more productivity per unit volume of membrane; B-Supporting toward oneself which could make regeneration to recover flux and C-Exact resilience within the mode of operation[21].

The aim of the present work is to produce an advanced nano CA membrane using adjacent PTFE and utilizing the new product in desalinating brackish water.

\section{Experimental}

\section{Materials}

The chemicals used throughout were Cellulose Acetate (CA) was delivered in the nano form (NCA) as a solution from Sigma chemicals,
Poly tetra Flouro ethylene (PTFE) membrane sheets (kindly supplied by El-Asher Co., 10th of Ramadan City-Egypt), Dimethyl formamide, formamide, and paraformaldehyde were delivered from Fluka, acetic acid, acetone, sodium hydroxide and sodium bicarbonate delivered as analytical grade from ADWIC-Egypt.

\section{Preparation of Membranes}

The casting solutions were prepared by dissolving the necessary quantity of NCA (1-6g) in acetone: Dimethyl formamide (2:1) mixture and adjusting the liquor ratio 1:20 according to a method mentioned elsewhere. The mixture was stirred until NCA getting the casting solution. The prepared casting solution was casted on PTFE membrane fixed on a glass plate, at ambient temperature and spread with a casting knife to a certain thickness $(140 \mu \mathrm{m})$, and then sunk in a bath containing cold water $5^{\circ} \mathrm{C}$, followed by exposure to air for $10 \mathrm{~min}$. [19].

Tests

SEM morphology

The surface morphologies of the functionalized cellulose acetate at various stages were characterized by using a JEOL JSM 840A (Tokyo, Japan), Scanning Electron Microscope (SEM) at an accelerating voltage of $15 \mathrm{KV}$.

\section{R.O. Tests}

Contact Angle measurement: Contact angle was measured using DSA100W-Wafer device Kruss Gmbh- Germany.

Salt Rejection and Salt Passage: The salt rejection describes the quantity of salt removed from the reverse osmosis feed water stream as percentage.

$$
\text { Salt Rejection }=\frac{\left(\mathrm{TDS}_{\text {Feed }}-\text { TDS }_{\text {Product }}\right)}{\left(\text { TDS Feed }_{\text {Fed }}\right)} \times 100
$$

\section{Salt Passage $=1-$ Salt Rejection}

\section{Feeding water Characteristics}

The characteristics of feeding water listed in Table 1, the ratio of cations and anions was not balanced exactly. This may be attributed to incomplete analysis of some of minor ions were not analyzed. Table 1 shows the total hardness of the incoming water (total of $\mathrm{Mg}^{2+}$ and $\mathrm{Ca}^{2+}$ 
TABLE 1. Chemical analysis of brackish water sample from a deep well in Belbis-Sharkya Governorate-Egypt.

\begin{tabular}{lccc}
\hline Anion & Concentration & Cation & Concentration \\
\hline $\mathrm{HCO}_{3}^{-}$ & 820 & $\mathrm{~K}^{+}$ & 96 \\
$\mathrm{Cl}^{-}$ & 520 & $\mathrm{Na}^{+}$ & 430 \\
$\mathrm{NO}_{3}^{-}$ & 170 & $\mathrm{Ca}^{2+}$ & 210 \\
$\mathrm{SO}_{4}^{2-}$ & 320 & $\mathrm{Mg}^{2+}$ & 130 \\
Total Anion concentration & 1830 & Total Cation concentration & 866 \\
\hline
\end{tabular}

ions) was $340 \mathrm{ppm}$. Moreover, the sum of the concentration of sodium and chloride ions was about $950 \mathrm{ppm}$ due to possible the increased use of chemical fertilizers that raises the nitrate ions concentration (170 ppm) according to the primary activity of the area of this study.

\section{NCA membranes Characterization}

The most effective factors governing the final structure of the asymmetric membranes are the concentration of polymer of the dope solution and

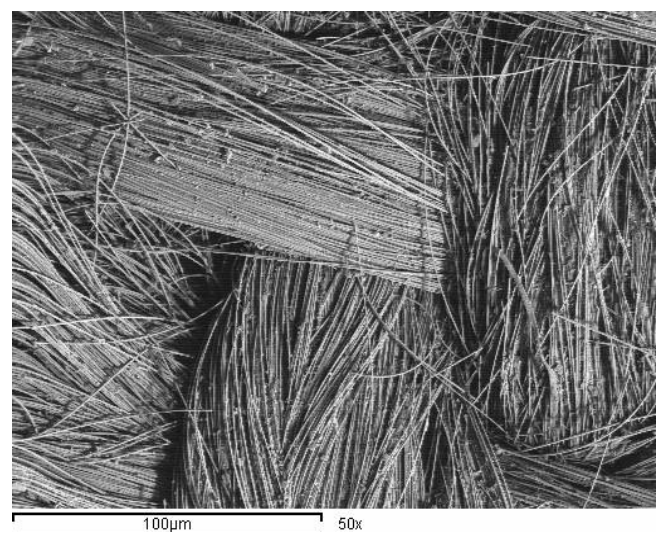

Fig. 1. Fiber glass woven fabric (PTFE).

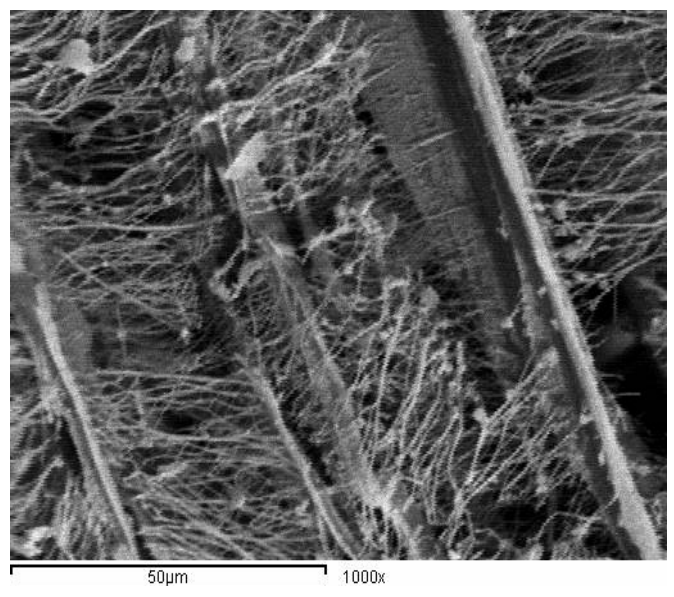

Fig. 3. A scanning electron microscope photography for the woven fabric sample with PTFE-NCA membrane on the top surface. the annealing temperature of the film. It is obvious that by increasing the concentration of polymer, the more compactness in the top layer and the decreased pore size distribution [20]. Meanwhile, by the higher the annealing degree, the higher is the ratio of crystalline domains in the structure of the polymer will occur which produces denser skin layer [21]. These parameters allow membrane designing via working at the pore size distribution and on the thickness of the dense skin layer. Asymmetrical NCA membranes were prepared via

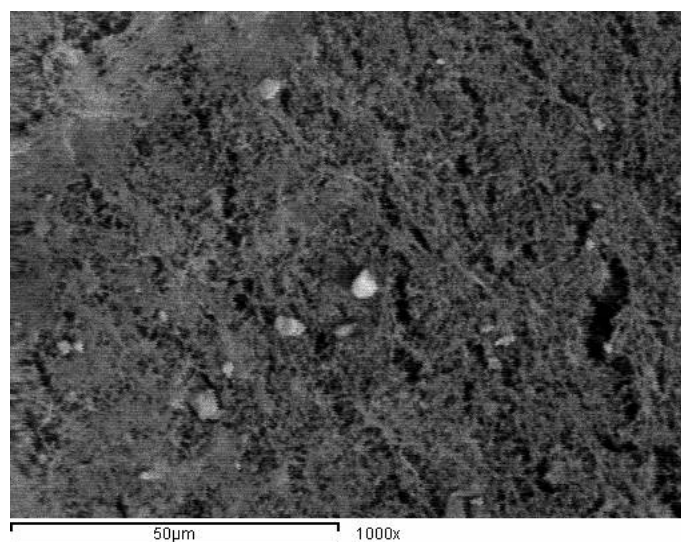

Fig. 2. A scanning electron microscope photography for the PTFE-NCA membrane.

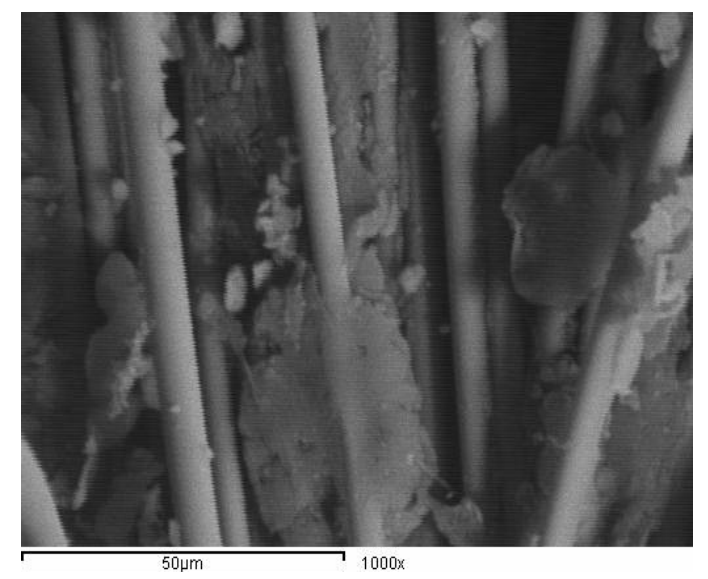

Fig. 4. Back side of the woven fabric sample with PTFE-NCA membrane on the top surface with two magnifications.

Egypt.J.Chem. 62, No.1 (2019) 
the inundation technique from 20 and 25 weight percent of polymer concentrations. Applying the annealing temperature range $60-90^{\circ} \mathrm{C}$, the thickness of the dry films were about $60-80 \mu \mathrm{m}$ depending on the initial concentration of the polymer in the dope solution. SEM graphs (Fig.1-4) using different magnifications indicate the asymmetrical structure for the produced materials composed of a top skin layer withstand by an open spongy like composition. Changing of both parameters include sturdy alterations of the permeability degree of the yield membranes [21].

Increasing the permeability with decreasing of the annealing temperature and concentration of the polymer indicating the untying of the produced structure and altering the distribution of the pore size from RO to NF materials. Meanwhile, maximum operating pressure for CA-20-60 was $0.8 \mathrm{Mb}$ as a result of decreasing mechanical strength as shown in Fig.5. The other samples were tested up to 1.5 $\mathrm{Mb}$. to seek for a connection between mechanical strength and high flux, the study restricted on materials those annealed between 70 and $80^{\circ} \mathrm{C}$.

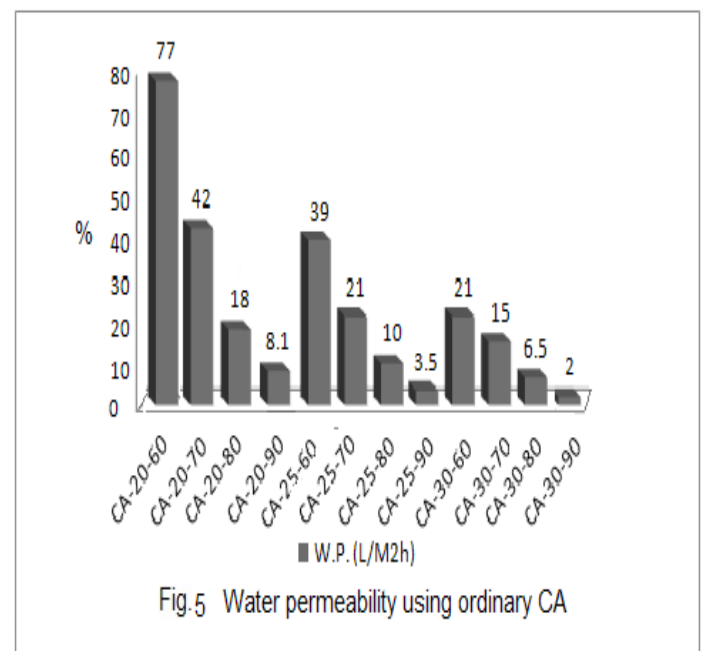

Fig. 5. Water Permeability using Ordinary CA (The first number refers to $\mathrm{CA}$ concentration as (g/l) and the second refers to the annealing temperature after casting in ${ }^{\circ} \mathrm{C}$.

\section{PTFE-NCA membranes Characterization}

PTFE-NCA combined membranes or simply (PCA) were obtained by overlaying a very fluffy layer of PTFE over the surface of NCA supports as shown by the SEM micrographs in Fig. 3a-d for CA-22-80 and PCA-22-80. The adaptation yields to increased uniform and smoother surfaces. Although, the SEM analytical data indicate a small pore hindrance of the top layer structure that had to be produced in a higher or lower penetration of PTFE within the NCA support morphology.
On comparison between the values of water contact angles produced for unchanged and membranes indicated in Fig. 6 proof that the surface amended by the PTFE overlying. The increased values presented for the PCA samples meet with the PTFE hydrophobic nature. Also, the outcome refers to a decreased contact angle for membranes produced from polymers with higher concentrations. Such behavior is related to how denser the structure of the upper layer surface is. Therefore, no clear difference was noticed with the annealing degree. It illustrates that such parameter affected on the film morphology more than on the surface structure.

\section{Desalination Behavior}

Comparing CA supports (CA-C-T) and the produced membrane (PCA-C-T) for the desalinating brackish water is illustrated in Fig. (6) Ongoing from pure to brackish water, the permeation rate declined to $10-20 \%$ for NCA supports and produced composite membranes, consequently. It must be obvious that increment is greater for the membranes those possessing the narrow pore diameter (CA-22-80 \& PCA-22-80).

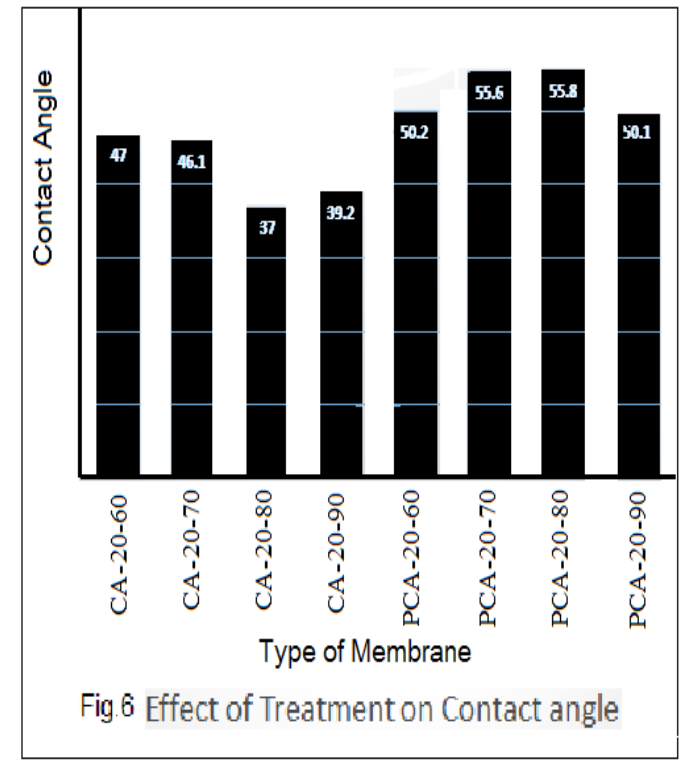

The best expression for the obtained data is the T.D.S \% rejection. As predicted the production circumstances influence sturdily the salt removal performance. Both factors of increased annealing temperature and concentration of polymer improved the salt rejection value from 66 to $90 \%$ for CA membranes. The surface alteration with PTFE increased the retention (PCA membranes). The increased value was remarked for the membranes performed at $70^{\circ} \mathrm{C}$. On the other hand, frequently no variation was noticed for 
TABLE 2. Chemical analysis of brackish water sample after desalination using PTFE-NCA at $60^{\circ} \mathrm{C}$ with 20 ppm concentration.

\begin{tabular}{|c|c|c|c|}
\hline Anion & Concentration & Cation & Concentration \\
\hline $\mathrm{HCO}_{3}^{-}$ & 98 & $\mathrm{~K}^{+}$ & 12 \\
\hline $\mathrm{Cl}^{-}$ & 57 & $\mathrm{Na}^{+}$ & 56 \\
\hline $\mathrm{NO}^{3-}$ & 22 & $\mathrm{Ca}^{2+}$ & 23 \\
\hline $\mathrm{SO}^{2-}$ & 38 & $\mathrm{Mg}^{2+}$ & 18 \\
\hline $\begin{array}{c}\text { Total Anion } \\
\text { concentration }\end{array}$ & 215 & TotalCation concentration & 109 \\
\hline
\end{tabular}

materials produced at $80^{\circ} \mathrm{C}$. It was suggested that the selection resulted from the NCA support in the case of the narrower pore structure. Table 2 illustrates the decrease in TDS for the untreated brackish water and after desalination using the PTFE-NCA composite, about $80 \%$ reduction in all anions and cations was found assuring the enhanced performance of the produced product.

\section{Conclusion}

CA-membranes reinforced with PTFE sheet were utilized as brackish water desalination membranes, different parameters were used to obtain the higher performance membrane such as dope solution concentration as well as the annealing temperature. The results indicated that the higher performance was obtained with composite membrane prepared with $20 \%$ and $90^{\circ} \mathrm{C}$. The study assured that using reinforced PTFE increased the composed membrane performance towards Water permeability, flux and salt rejection $20 \%$ more than the normal CA-membranes.

\section{References}

1. Qtaishat M., Rana D., Khayet M., Matsuura T., Preparation and characterization of novel Hydrophobic/hydrophilic polyetherimide composite membranes for desalination by direct contact membrane distillation, Journal of Membrane Science, 327, 264-273 (2009).

2. Durmaz E.N., Zeynep P., Emecen C., Cellulose-based membranes via Phase inversion using [EMIM] OAC-DMSO mixtures as solvent, Chemical Engineering Science, 178, 93-103( 2018).

3. Kosiol P., Hansmann B., Ulbricht M., Thom V., Determination of pore size Distribution of virus Filtration membranes using gold nanoparticles as their correlation with virus Retention, J. of Membrane Science, 533, 289301 (2017).
4. Hao-Cheng Yang, Jianquaa Luo, Yan Lv, Ping Shen, Zho-Kang Xu, Surface Engineering of Polymer Membrane via mussel-inspired Chemistry, J. of Membrane Science, 483, 4259 (2015).

5. Li X., Sotto Ar., Sheng Li J., Bruggen B. V., Progress and Prospection for synthesis Of sustainable Anti-fouling composite membranes containing in situ generated nanoparticles, J. of Membrane Science, 524, 502-528 (2017).

6. Stoller M., Mendes R. S., Advanced control system for membrane processes based on the boundary Flux model, Separation and Purification Technology, 175, 527-535 (2017).

7. Yinping B. D., Zheng C. G., Liu M., Zhu H., Submerged nano- Filtration of biologically treated Molasses fermentation wastewater for the Removal of Melanoidins, Chemical Engineering Journal, 223, 388-394 (2013).

8. Yang Y., Zhao C., Wang Y., Fan W. and Luan Z., Effects of ion concentration and natural organic Matter on arsenic (V) Removal by Nanofiltration under different Trans membrane pressures, Journal of Environmental Sciences, 25 (2), 302307(2013).

9. Shibuya M., Sasaki K., Tanaka Y., Yasukawa M. and Matsuyama H., Development of combined Nanofiltration and forward osmosis process for production of ethanol from pretreated rice straw, Bioresource Technology, 235, 405- 410 (2017).

10. Zhang Y., Yanlei S., Peng J. M., Zhao X., Liu J., Zhao J. and Jiang Z., Composite nanofiltration Membranes prepared by interfacial polymerization with natural 
Material tannic acid and trimesoylChloride, Journal of Material Science, 429, 235-242(2013).

11. Heck N., Paytan A., Donald M., Potts C., Haddad B. and Petersen K. L., Management priorities for sea water desalination plants in a marine protected Area: a Multi-Creteria analysis, Marine Policy, 86, 64-71(2017).

12. Mohory A., Sadeghi M., Mobeb A., Heavy Metal Elimination from drinking water using Nanofiltration Membrane Technology and process optimization using response surface, Desalination, 352, 166-173 (2014).

13. Vergili I., Application of Nanofiltration for the removal of carbamazepine, diclofenac and Ibuprofen from drinking water sources, J. of Env. Management, 127, 177-187 (2013).

14. Kim S., Oung K., Chu H., Al-Hamadan Y. A. J., Park C. M., Jang M., Kim Do-Hyung, Heo M.Y. J., Yoon Y., Removal of contaminants of emerging concern by membranes in water and Waste water: A review article, Chinese Eng. J., 335, 896-914 (2018).

15. Lv J., Zhang G., Zhang H., Yang F., Exploration of permeability and antifouling performance on Modified Cellulose acetate Ultrafiltration membrane with cellulose nanocrystals, Carbohydrate Polymers, 174, 190- 199 (2017).

16. Bodzek M., Advances in Membrane Technologies of Water Treatment, Woodheed Publishing series in Energy, 465-517 (2015).

17. Kowalski K. P., Chapter 8: Advanced Arsenic removal technology Review Book Chapter, Chemistry of Advanced Environmental Purification Processes of Water Fundamentals and Applications, 285-337 (2014).

18. Weijie,Y. J., Yu Q. Y., An Q., Liu L., Zhau Y., Gao C., Recent developments in nanofiltration Membranes based a nanomaterials, Chinese J. of Chemical Engineering, 25 (11), 16391652(2017).

19. MariënIvo H., Vankelecom F.J., Optimization of the ionic liquid-based interfacial Polymerization system for the preparation of High-performance low-fouling RO membranes, Journal of Membrane Science, 556, 342-351(2018).

20. El-Saied H., Basta A. H., Barsoum B. N., Cellulose membranes for Reverse Osmosis: Part I. RO Cellulose acetate Membranes including a composite with polypropylene, Desalination 159, 171-181(2003).

21. Rezakazemi M., Matsuura T., Thermally stable polymers for advanced highPerformance Gas Separation membranes, Progress in Energy and Combustion Science, 66, 1-41 (2018).

22. Yoong P., See H., Frederico T., Ferreira C., Livingstonm A. G., The influence of membrane Formation parameters on the functional Performance of organic Solvent nanofiltration membranes, Journal of Membrane Science, 299 (1-2), 236250(2007).

(Received 20/5/2018; accepted 29/8/2018)

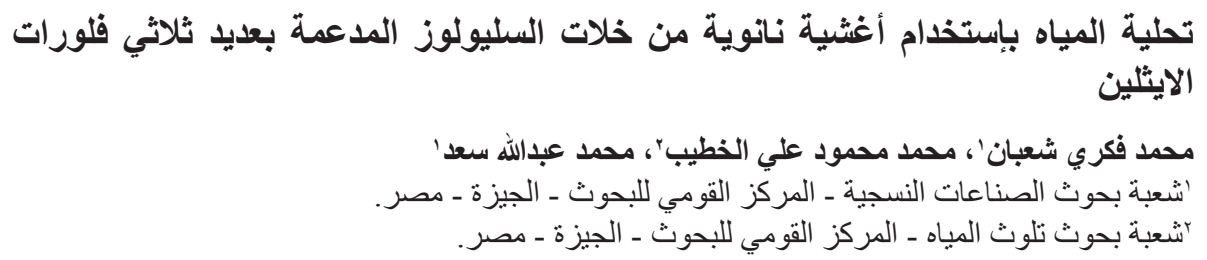

حيث تم تدعيم الأغشية المكونة من خلات السيليولوز بشر ائح من عديد ثلاثي فلور ات الإيثليلين و إستغلالها كأغثية

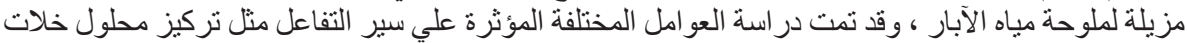

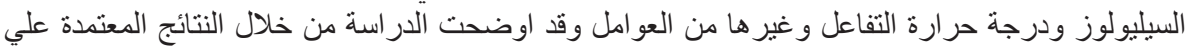

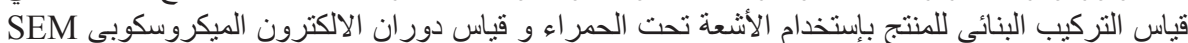

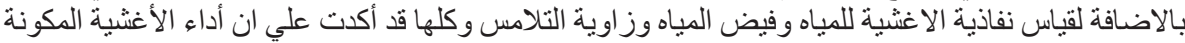

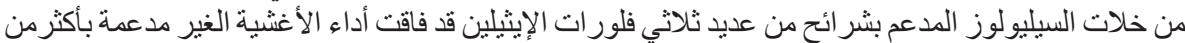

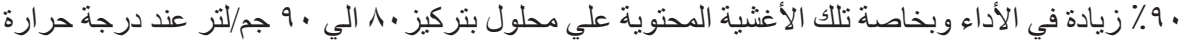

